\title{
Life according to ME: caught in the ebb-tide
}

\section{Olaug S. Lian and Frances Rapport}

Later published in:

Lian, Olaug S. \& Rapport, Frances (2016). Life according to ME: Caught in the ebbtide. Health: 20(6), 578-598. DOI: 10.1177/1363459315622041.

When refering to this paper, please use this reference.

Corresponding author:

Olaug S Lian, Department of Community Medicine, Faculty of Health Sciences, University of Troms $\varnothing$ - The Arctic University of Norway, 9037 Tromsø, Norway. Email: olaug.lian@uit.no

\begin{abstract}
In this article, we explore the role of 'place' in shaping people's illness experiences through a data-led inductive case-study based on experiential data from people living with myalgic encephalomyelitis (ME) in Norway. Our main aim is to understand how they experience, interpret and attach meaning to various places in which they reside, and how they construct the course of a life influenced by chronic illness. The study is based on stories containing photographs and written texts, received from 10 women and men. In their stories, they describe those places where they experience their illness in the least and most taxing ways. Through a narrative and photographic analysis of their stories, we explore how they perceive the relationship between place and illness as experienced, managed and endured. Our analysis is based on a placesensitive sociology, in which we approach place both as physicality and a symbolic construction. The participants describe how a wide range of places are intimately linked to their illness experiences, and they interpret these links by referring to both physical and symbolic factors. They describe their lives in terms of a need for equilibrium between activity and rest. Risk is a strong underlying theme: whatever they do, they risk losing something. Most of all, the participants describe how they are looking for places to escape to and from. Places to escape to are those places where privacy and peace can be found, which primarily revolve around being at home. Places to escape from are those places that make their energy 'slowly ebb away'.
\end{abstract}




\section{Introduction}

The notion of 'place' matters in terms of health and illness because our bodies and our individual and social activities are always emplaced (Casey, 2001). Through physical and symbolic aspects, empirical settings of places shape opportunities and constraints that influence our health, the way we perceive health problems, the social consequences of being ill, our ability to engage in everyday life, and our ability to fulfil our social roles (Andrews, 2014; Crooks and Chouinard, 2006; Gesler and Kearns, 2002; Kearns, 2014). Some places are seen as 'therapeutic landscapes' affording healing powers, and most societies design special places for healing (Gesler, 1992). Virtual places, made possible through new communication technologies, enable people to discuss health-related issues wherever they are physically located (Lian and Nettleton, 2015). Cultural norms prescribe culturally acceptable places for revealing bodily ailments.

In this article, we qualitatively explore the relationship between place and illness experiences of people suffering from Myalgic Encephalomyelitis (ME). As the symptomatology of this illness relates to place (fatigue, sensitivity towards sensory impressions like sound and light and reduced movement abilities), we can assume that place is particularly important for the illness experiences of people with this chronic condition. Our aim is to draw on experiential knowledge about how those living with ME make sense of place, and how the place and illness nexus shapes their everyday lives. Within this we ask: What is the role of place in influencing the ways in which people suffering from ME experience, manage and endure living a life with a debilitating chronic illness; how do their illness experiences change in relation to places in which they reside; and why do certain places afford restorative powers? 
To explore these questions, we asked ten women and men with ME to situate their illness experiences, and tell us - through photographs and words - how they perceive different places can relieve or intensify the burden of their illness. The datasets entail multimodal narrative accounts (from now on called "stories") created by six women and four men living with ME in Norway. We gathered the data through a combination of photographs (they took the photographs themselves) and autobiographical texts (they wrote about their own experiences), and we analysed the data using a data-led, inductive, thematic analysis approach (Braun and Clarke, 2006). Visual storytelling involves "putting cameras into the hands of those being studied" (Harper, 2012: 188). The underlying idea behind this method, as with autobiographical texts, is to appreciate people's own experiences, and recognise the significance of their perspective (Wang and Burris, 1997; Drew et al., 2010). Their texts offer insights about how the participants consciously assign meaning to their own perceptions and experiences, including their 'sense of place'. Their photographs, on the other hand, owe some of their strengths to "the unintended details they contain" (Radley and Taylor, 2003: 131). In addition, they offer insights into the physical settings of people's lives, and serve to "re-anchor the subject in the physical world” (Rugg, 1997: 2). Basing our analysis on experiential data consisting of "photography placed in conjunction with auto-biographical texts" (Rugg, 1997: 2) means that we benefit from the complementarity of two different data sources that both draw on people's own accounts of their lives.

We frame our study within a sociological perspective sensitive to the issue of place (Gieryn, 2000). We emphasise the experiential features of 'place' (Casey, 1997), and define it as a space that has been "invested with meaning" (Domosh and Seager, 2001: xxii). A place is a construct of experience that may or may not have a 
physical location. When physically located, a place is defined as a limited and localised portion of bounded space (geographical location and physicality), demarcated by definite or indefinite physical or symbolic boundaries (Eyles, 1985; Gesler and Kearns, 2002). The physical dimension consists of a physical location, a geographical position, and a spatial closeness or distance, and its physical attributes can be described in terms of size, shape, boundaries, objects, artefacts or people occupying its spaces. The symbolic dimension is the ascribed symbolic meaning that we - the interpreters - assign to it, either consciously or "less-than-fully" consciously (Andrews, 2014: 1). What a place signifies is individually interpreted, but culturally embedded (Lian, 2007). Whether physically located or not, a space becomes a place when it is experienced, identified, named and symbolically constructed as people assign meaning to it. A place is therefore a symbol of something, beyond the physical. The symbolic meaning is part of our 'sense of place' (Eyles, 1985). In our analysis, we explore how people experience, manage and endure their illness in relation to the two main dimensions of a place; the physical and the symbolic. In the final discussion section of this paper we reflect on the results of our study in relation to chronic illness in general.

\section{Background}

ME is a medical term for debilitating long-term fatigue, characterised by a postexertional fatigue which does not disappear after resting, accompanied by symptoms such as malaise, dysregulation of body temperature, increased sensitivity towards sensory impressions, bowel problems, sleep disturbance, cognitive problems, muscle pain, muscle weakness and reduced mobility (Carruthers et al., 2011). The severity varies between mild (approximately 50\% reduction in activity), moderate, severe and 
very severe (bedbound and dependent on help for physical functions). Diagnosis is primarily based on assessing reported symptoms and case histories against 1 of more than 10 existing sets of diagnostic criteria (Brurberg et al., 2014).

ME is an illness dominated by physical symptoms, which according to Nacul et al. (2011) can lead to people's physical faculties being be more impaired than their mental wellbeing (Nacul et al., 2011). Apart from Nacul et al. (2011), however, previous research on illness experiences has concentrated on psychological and social issues for people with ME, such as emotional distress, stigma, social isolation and identity reconstruction (Edwards et al., 2007; Moss and Dyck, 2002), often related to loss of career, income, and social networks (Whitehead, 2006), or feelings of being disbelieved (Anderson et al., 2012). Some of these consequences stem from the illness itself and its symptoms, while others follow from having a chronic condition and a diagnosis that is medically contested and therefore perceived as stigmatising. The literature also discusses the coping strategies for people with ME, which include acquiring knowledge, keeping a distance from others, learning about physical and mental limitations, and finding the right balance between activity and rest (Larun and Malterud, 2007; Drachler et al., 2009).

According to previous research, we know very little about the relationship between place and illness experiences for people with ME. A study by Pini and Soldatic (2012) makes a rare exception. Their study is based on the story of 'Sharon' who lived with ME for nearly 30 years. Sharon describes how her attempts to hide and manage her illness led to social isolation. Her rural residence, however, provided her with some kind of reprieve: "So cognizant is Sharon of the potential for judgment and censure that she finds some solace in her rural isolation because her house (and its 
state of cleanliness) is not on constant view for the community" (Soldatic, 2012: 389). Sharon described how her quiet and beautiful rural surroundings had "a restorative impact" (Soldatic, 2012: 396). On the other hand, she also found that the traditional culture of the rural area (family- and gender-related norms and values in particular) created some problems. A number of times throughout the interview, for instance, she spoke about her husband's attitude towards the 'messiness' of the house, a situation she presented as magnified because she lacked a legitimate medical diagnosis: "I had a partner who didn't believe I was sick" (Soldatic, 2012: 392). The ways in which Sharon attempted to hide her illness by isolating herself is illustrative of the sense of being stigmatized, misinterpreted and even doubted - something that people with ME often experience when engaging with others, both inside and outside the medical system (Anderson et al., 2012; Moss and Dyck, 2002; Whitehead, 2006).

\section{Study design}

The present study, described in this paper, is part of a larger, six-year research project aiming to explore the experiences of people with ME through a wide range of data capture methods, including survey data about patient experiences (Lian and Hansen, 2015), a study of internet blogs (Lian and Nettleton, 2015) and a comparative study of contemporary and historical medical literature about ME (Lian and Bondevik, 2015). A reference group consisting of people with ME, representatives of patient organisations and doctors has been connected to this project from the beginning of the six-year project (2012) to advice the research team as work progresses and monitor aspects of the process. Some of these representatives (namely people with ME) have been involved in planning this part of the project. The first author had a meeting with the representative group and presented the preliminary plans to them. Final decisions 
on the design were made after these discussions. Their input has been of vital importance, especially in relation to the final wording of the questions raised in the participant brief.

\section{Participants}

In April 2014, we invited 15 purposely selected people with ME to participate in the study. The candidates were suggested by members of the project reference group, based on instructions about inclusion and exclusion criteria, formulated to ensure diversity in age (20-60), gender (equal distribution), health status (very severe degree of ME excluded), duration of symptoms (at least six months) and place of residency (rural/urban, inland/coastal, north/south). These inclusion and exclusion criteria were clearly explained to the members of the project reference group before candidates were suggested. Ten of the potential participants then contacted the project manager (first author) via phone or email to ask questions about the study before they made their decision, following which they all agreed to participate (Table 1). The other five declined to participate due to ill health.

\section{Data capture}

Participants were asked to tell - through photographs and words - about their illness experiences in relation to those places in which they reside in their everyday lives by addressing the following two questions: "If places where you reside in your everyday lives make a difference: 1) in which environments do you experience your illness as least taxing, and 2) in which environments do you experience your illness as most taxing?" We formulated the questions as broadly as possible to encourage the participants to give us their holistic views on their illness experiences (recognising that people rarely compartmentalise their life into physical, mental and social 
components), and to limit researcher influence. Keeping the task as simple as possible was also undertaken to respect the health problems (fatigue and cognitive difficulties) of people with ME (as advised by the members of the reference group). We asked each participant for an autobiographic story, created by a combination of text (maximum two pages) and photographs (maximum ten). All participants delivered both photographs and texts (Table 1). They all related their text to their photographs in a way that appeared integrally linked and mutually supportive. The texts were translated from Norwegian to English (except one that was submitted in English). In order not to lose the finer detail and nuance through translation, and to ensure linguistic conformity and consistency, the first author continuously checked the translated texts against the original Norwegian texts during the analysis.

Table 1 Participant details

\begin{tabular}{|l|c|c|c|c|c|}
\hline & Age group & Location $^{\text {a }}$ & Photographs & Word count & Translated by \\
\hline 6 women & & & & & \\
\hline W1 & $40-50$ & Urban & 10 & 1570 & First author \\
\hline W3 & $20-30$ & Urban & 8 & 1300 & Professional \\
\hline W4 & $50-50$ & Urban & 9 & 1650 & First author \\
\hline W5 & $50-60$ & Rural & 10 & 1100 & Professional \\
\hline W6 & $30-40$ & Urban & 5 & 540 & First author \\
\hline 4 men & & & 10 & 180 & Na. \\
\hline M1 & $30-40$ & Rural & 9 & 1420 & First author \\
\hline M2 & $20-30$ & Urban & 2 & 680 & First author \\
\hline M3 & $40-50$ & Rural & 7 & 1200 & Professional \\
\hline M4 & $40-50$ & Urban & 10 & 1360 & Na. \\
\hline Range & $26-58$ & Na. & $2-10$ & $540-1650$ & \\
\hline
\end{tabular}




\section{Analysis}

Photographs and texts can be analysed as 'stand-alone' products, but in addition, each can extend our understanding of the other (Drew \& Guillemin, 2014; Rapport, Doel and Elwyn, 2007; Rugg, 1997). During the analysis, we treated each participant's contribution as one story, presented through textual and visual means.

We began by conducting a thematic analysis of their stories, first on a participant-by-participant basis (to respect the uniqueness of each story), and then as a combined dataset. First, we identified the ways in which each person's dataset related to the research questions and to the brief participants were given, to explore places that were most and least taxing to them (Braun and Clarke, 2006). Visual data were also considered in terms of the colour and styling of the image, the chosen format of each image, the way places that were presented did or did not contain objects that could be considered for their comforting or anxiety-raising qualities, and the way in which objects were grouped and arranged to 'affect' the viewer (Author, 2007). We also discussed the organisation of the places presented in terms of how each visual image differed, and similar aspects of places identified in terms of their ability to stimulate activity or stillness. With the texts in mind, we assessed visual patterns of form and function, and compared and contrasted those to the written words about form and function (van Manen, 1990). We then grouped extracts from all texts and grouped specific images together according to two main emerging themes: being at home, and being away from home. For each of these themes we created subcategories (and sub-groupings) in relation to places and artefacts participants included in their stories. Finally, we searched for patterns of divergence and convergence across all selected themes through an exploratory, case-led approach, while re- 
examining our interpretations, and fine-tuning our views, towards a more refined theoretical construction (Charmaz, 2014).

\section{Ethics}

We received ethical approval for this study from the Norwegian Data Protection Official on the $2^{\text {nd }}$ of April 2014 (id. 38160).

\section{Results}

Most participants structured their presentations in relation to two main themes: being at home, and being away from home. By 'home' (in Norwegian "hjemme”) they usually referred to a narrow meaning of the term: their place of residence, that is to say, the house or flat in which they live. In the following we stick to both this structure (home - not home) and the narrow meaning of home (whenever 'home' is used differently we will make that clear). We present their words in verbatim form. In appreciation of the difference between participants' own words and researchers' interpretations of those words we attempt in this paper to separate the two elements as much as possible. This decision is mainly due to the sensitive nature of their stories, but also because they express themselves in such a thoughtful, vivid and detailed manner. Because all participants used photographs interlinked with their written stories, we present them corroboratively.

\section{At home}

Starting with stories about being at home, we first move from room to room before we turn to their artefacts. 


\section{Being "at home"}

Most participants describe being inside the home - meaning the place where they live - as the least burdensome place for them to be:

"I am largely housebound because it is at home that I can get most rest (W5)."

"At home. Everything is arranged to make things easier for me - physically, mentally and interpersonally (M2).”

"I experience my illness as least taxing when I am at home with myself ... In the winter-season, when it becomes difficult to move outside, I almost hibernate inside the house (W1)."

The location of the home is important for many:

"The view and the light are an important reason why I find my house a good place to be. I live high up and free, seeing the fjord and the sea, and can follow changes in weather and wind ... I can watch the sunrise from my bed (W4)."

At home is a good place to be, not only but in particular because of the physical aspects of the home environment:

"All those who come regularly to this house are familiar with my situation and know my circumstances. This means I don't need to explain that there are things I can't manage ... and I am not embarrassed to ask for help (M2)."

In a poem, one woman describes coming "home" to the place where she lives negatively ("the good place" she refers to is her holiday cottage, which is a place she describes in much the same way as others describe their homes): 
"Every time I come home from the good place I feel the pressure, as if everything is pushed closer, limits freedom, even thoughts. It could be something to do with the location, perhaps, as if the house always pushes the light away from itself, from me. The couch that is so deep, difficult to get up from, the disturbances from thoughts about everything I ought to do that I do not do; that gnaw and corrode, that are intensified by happy children's voices far away, a train, a car ... (W6)."

\section{Rooms and artefacts}

Often, participants' descriptions relate to a specific room or a piece of furniture in their homes. Usually, they describe their bedrooms, beds or sofas as good places:

\footnotetext{
"The bedroom and the bed are by far the best place for me to be if I need maximum rest. There it is cool and quiet, and among other things I avoid the humming noise from the refrigerator that can sometimes be annoying in the living room. The light from the windows can be dimmed with curtains if necessary, and I have a short walk to the toilet (W2)."
}

"I stay in bed for $10-12$ hours per day. At night, under the duvet; in the day (after I have got up and dressed myself in the morning) I lie on top of the bedcover under a woollen blanket. The bed is good (W4)." (Photograph W4 in attachment.)

One woman experiences her bedroom differently:

"It is hard to admit, but I always become sad when I go into the bedroom. I feel lonely and alone in the big bed. I feel what I miss and long for (W1).”

Beds and sofas are mentioned by nearly all participants, usually in relation to their need for rest:

\footnotetext{
"Resting is an important task which I have to carry out to preserve my life. I'm laid down for charging ... After the rest, I am "free" again (W3)."
} 
One woman describes how she tries to hide visual traces of her need to lie down a lot, traces that demarcate her "otherness", by describing a blanket she uses to cover the bedlinen on her sofa:

"I have a thin summer duvet, which I've made a cover for using linen fabric and a patterned fabric from Ikea, so it doesn't appear like it's made for a bed (W3).”

The bed or sofa can also be a place from which to observe or communicate with the outside world, or gather information from the internet:

\footnotetext{
"It was clear to me early on that if I was going to return to a normal life, the responsibility lay with me. I have therefore done some thorough reading on the internet (with PubMed as my main source) about the diagnosis, research findings and treatment (M4).”
}

Several participants describe how they keep a lot of things within easy reach from the bed or sofa:
"I am very fond of my sofa, and this is where I spend most of my days ... This is more of a work space where I sit down if I have to do something constructive on the laptop, write cards, wrap gifts or do something else creative (W2)."

“At times I am surrounded by for example knitting equipment, folders with papers related to research on my family history, the mail, a camera with its equipment, a dark green knitted vest which I lay over my eyes so it gets dark when I rest for a while, dishes from my previous meal, and occasionally a bunch of newly washed socks that need to be sorted (W3)." (Photograph W3 in attachment)

While describing her sofa, she also reflects on her future: 
“... if I were to get well one day, I might come to shun this sofa like the plague (W3).”

The value of creativity, and the artefacts that correspond with creative outlets, is mentioned by several participants:

"In my bedroom I have a sewing cabinet. There stands my sewing machine, ready to use. I don't even have to lift it out, if I can't bear to. I can just open the door, put the plug in, and voila! I am full of dreams of things I wish to create (W3).”

Another woman describes the pleasure derived from reading books as a kind of escape:

"And in the middle of it all, a pile of books that constantly remains just as high, a distraction, a kind of escape, a place to survive, a breathing space (W6)."

\section{Ambiguity and risk}

Being at home is described by participants as the least taxing place for them to be, but this notion is not without its inherent ambiguity:

"I spend most of my time at home ... being quietly at home causes the least physical and sensory strain, while mentally it can make me restless and depressed if I remain alone for a long time (W4)."

"The sofa corner represents my everyday life, where I feel normal. At the same time it represents a life which, when seen through the eyes of others, seems anything but normal (W3)."

Another woman expresses similarly ambiguous thoughts about her kitchen:

"It makes me feel good to experience creating something, even if it is only a simple dish. Nevertheless I choose to classify the kitchen as somewhere that places more 
strain on me, as it means that I have to stand a lot, bend down to get things from the cupboard and the oven etc. (W2)." (Photograph W2 in attachment)

Sounds from other parts of the house can be disturbing because they are noisy, or remind them of something emotional:

"I have to eat my breakfast in bed, silently crying for myself when I hear the noises of the family. Why can't I just be "normal"? (M1)."

A similar "disturbance" can also result from household artefacts, because of what they symbolise:

"The dancing-shoes I used while dancing swing, salsa and tango, just stand there collecting dust, together with the ski-boots. Party shoes, with or without high heels, trainers, mountain-boots and rubber-boots are stowed away, in hope for a better future (W1)."

\section{Discussion}

When comparing their stories it seems that home is the place where they experience their illness as least straining (for all participants except one). Home is a place that could be described as a therapeutic landscape with a restorative power: At home, they have the tranquillity and freedom they need to regain their energy. At home, they are protected from the public gaze: they can hide signs that demarcate their "otherness" (for example by creating a blanket that does not look as if it was made for a bed), and they do not have to explain or justify their actions to anybody. At home, they can find meaning in creative activities. At home, lights can be dimmed and curtains drawn, and they have everything they need within easy reach. Within their homes, other people can be tolerated (predominantly family members and perhaps a few close friends), but only for short periods of time. At home, they can manage to come to terms with their 
lot, see things that are beautiful, moving or good, and accept what is good in a life that is radically limited by illness.

Although being home is the least taxing place for them to be, they describe this place ambiguously (as they do with most of the places they describe). Being at home to protect themselves from physical and sensory strain is something they have to do, but being alone at home for long periods of time can also be straining because it is, in a sense, a solitary confinement. They portray home as a sanctuary, but also as a "cave".

Photographs relating to the places they call home can be classified into four main categories: photographs of rooms, furniture, artefacts and gardens. People other than the participants themselves are rarely present in these photographs.

\section{Away from home}

In stories relating to not being at home, the participants draw a main distinction between busy public places and quieter surroundings,

\section{Busy public places}

All participants describe places outside the home, such as theatres, cinemas and shopping centres, as taxing:

\footnotetext{
"There are some places I try to avoid, as they appear as straining. I am rarely at the cinema because of the high sound level. I do not go to concerts anymore, and I also avoid other places where one has to stand in a queue to get in (W1)."
}

Another woman describes the noise and lightning inside a theatre as unpleasant: 
"Crowds and a lot of talking all around me are incredibly unpleasant. So, when the lights dim/go out and the performance begins, the experience changes completely (W4).”

Supermarkets and shopping centres are the same:

"One of the most exhausting things is food shopping at the store, both because of the sound level and all the visual noise ... I do my food shopping either early or late ... Then I avoid standing in a queue (W1).”

Meeting people at other places than home can be a strain, except for close relatives and perhaps close friends. The youngest participant describes her enjoyment of visiting her mother:

“...it is lovely to be at Mum's, where dinner is often served and where I can be social without having to go anywhere (W2)."

One man reflects on the symbolic meaning of the harbour:

“The harbour isn't far away. Here, the positive emotions don't surface so easily. I think it is because I am reminded of how it used to be to work and travel (M3).” (Photograph M3 in attachment.)

\section{Gardens and natural landscapes}

Several participants describe sitting in the garden, especially if it is sunny, as a strain:

"Lovely to be outdoors enjoying the sun, but unless I am having a very good day, I feel my energy slowly ebbing away ... Outside there is the noise of cars on the road, the temperature is more changeable (W2)."

“...finding peace and quiet in the sunshine can be difficult ... I might just as well go back into my "cave" (M4)." 
“Occasionally I can go out in the garden. It happens perhaps once or twice a year.

Then I sit and watch the flowers, and I take the opportunity to take some photographs that I can look at later. If I can manage, I talk to my neighbour (M3).”

A woman who lives in quieter surroundings finds it easier to stay outside:

“As soon as I wake up, I place myself outside with coffee and breakfast. The birdsong is life-affirming (W1)."

One woman writes about the view from her balcony:

"In the summer when there are leaves on the trees, you can stand in the middle of this little forest, and not see anything but the trees. I don't go there very often, but I can see it from my balcony, and I know it's there (W3)."

Several others describe a sense of longing when they reflect on natural landscapes:

"I want to go out! I want to feel the wind, show my daughter the world outside, enjoy the nature (M1)."

"I think about all those trips to the cabin I went on when I was well, and memorise the beacons on the mountain, the tracks in the wood, the polished slopes of naked rock, and not least the atmosphere when the fire lit up the night sky ... I dream about previous mile-long skiing trips on silk snow, and night-baths in sun-warmed, phosphorescent ocean (W1).”

Another woman writes about being in her mother's cabin:

"I can only go for short strolls around the cabin walls, but I read a lot of maps and look at possible hikes that I may be able to manage one day. Being here brings me peace, and the experience of being on a mountain hike (W4)." 
Being in natural landscapes is something most participants describe in positive terms:

"The water turns, catches the sun in flakes, throws the dust up to me.

The birds twitter, call, tell me that I am alive (W6).” (Photograph W6 in attachment)

\section{Ambiguity and risk}

Generally, they describe being anywhere outside their homes both positively and negatively at the same time:

"The places I go to often affect me positively and negatively at the same time, in both a practical and a deeper sense. Possibilities and constraints are closely entwined (W3)."

"I had to lie down for days after my last visit to the garden! (M3)."

"The places that make me most happy can often be places that are also most taxing for the illness - for example walks on the beach with friends, out shopping, holiday trips and so on (W2)."

Being outside home means moving between different places and that is taxing for most of them:

"I am a city girl, and for instance I enjoy being in [city name] busy main street or at a café (so long as I am feeling well), but my energy soon ebbs away in situations like that (W2)."

Several participants reflect on the risk of trying to stretch the borders of their limitations by visiting taxing places that nevertheless they enjoy:

"If I try to stretch the borders, I risk losing some of the little freedom to act that I have (W3)." 
"Having pushed myself too much, it's time to pay (M1)."

\section{Discussion}

When comparing their stories we see that places away from home are often most taxing for participants, particularly crowded and noisy places such as busy city streets, shopping centres, theatres, cinemas, and places with people that are not part of their "inner circle". These are places that they dread and long for at the same time, and as a consequence, these are places they usually avoid.

Natural landscapes have previously been described as 'landscapes of healing', because "simply getting out into nature has a therapeutic effect" (Gesler \& Kearns, 2002: 121). Natural landscapes - in presence and absence - feature prominently in all participants' texts and photographs. Being in natural landscapes is something that everyone describes positively, and with intense emotion, but often as a desired reality; as a place longed for and dreamed about. They can visit these places even though this takes its toll (if the travails of a journey can be overcome), but only fleetingly and for short bursts of time, which they sadly regret. Their absence is deeply felt. Ironically, the pleasure of these places also accounts for the strain that they create, diametrically opposed to therapeutic landscapes. Losing the ability to visit places they once enjoyed seems to make them more aware - in retrospect - of what these places used to mean to them.

The same ambiguity that is seen in their descriptions of being at home is voiced in their descriptions of being away from home. Wherever they are situated, and whatever they do, "possibilities and constraints are closely entwined". This dualism is most strongly expressed when they describe places they would love to 
visit, but their illness prevents them from managing to do so, either because of the strain it imposes on them or because of the costs of moving between places.

Photographs related to the outdoors are varied, but natural landscapes predominate.

\section{Narrations of illness and place}

Through similar yet richly varied stories, created by closely linked words and photographs, the participants in this study tell us about how place and illness experiences are totally integrated in their everyday lives. In factual and poetic presentations they describe how various places - whether real or imaginary - affect the ways in which they experience, manage and endure their illness, their ability to take part in activities within these places, and the restorative powers of these places (how different places relieve or accentuate their illness experiences). Although they describe their experiences in relation to a wide range of places (homes, gardens, shops, supermarkets, city streets, theatres, cinemas, harbours, holiday cottages and natural landscapes), they emphasise the inside of the home: the rooms, the furniture, the windows, the artefacts, and the short distance to the toilet. They base their descriptions on their sense of place, which "connotes the meaning, intention, felt value, and significance" (Gesler, 1992: 738) that they give to various places. By visualizing what is also communicated through words, their photographs add to our understanding in a way that makes their experiences easier to comprehend.

\section{Caught in the ebb-tide}

The participant's present detailed descriptions about how visiting taxing places makes their energy "slowly ebb away". 'Ebb' describes a situation where periods of progress 
and success are followed by periods of trouble and difficulty. As a metaphor, 'ebb' denotes a specific movement towards decline. Ebb is also found in 'ebb-tide': the period of time between high and low tide when water flows away from the shore, only to return again a little later. This metaphor, indirectly suggested by one of the participants (W2), captures a vital part of their stories. The rhythm of the rise and fall of their energy varies considerably between places and situations, and they can influence the process by adapting their activities to what they have previously experienced, but no matter how they adapt: Living with ME means that your energy easily ebbs away, and only returns very slowly.

\section{The balancing act}

A vital part of their attempts to adapt to their challenging situation is to constantly search for the right balance between activity and rest, excitement and peace. Rest is not a pleasure, but a necessity. Finding the right balance and timing is difficult, and failing to do so means that "it's time to pay". Uncertainty and risk are strong underlying themes: whatever they do, they risk losing their hard-earned energy, and thereby their freedom (if their timing is not right, and they go "against the flow"). While reflecting on these risks, they reminisce on their past and hope for a better future.

The search for the right balance between activity and rest is closely linked to the notion that for the people in our study, there are places in which they wish to escape to, and places they wish to escape from. A vital part of this balancing act is to constantly search out those places in both categories that support or hinder them in their lives. Places to escape to are enabling; they enable them to deal with their ailments and regain their energy. For all of them, that place is their home. Places to 
escape from (all places other than home) are taxing places. These escape-routes do not liberate them from their illness: ME is ever-present and limits their freedom of movement, their ability to socialise, their ability to live with and around others, and live as others do.

The search for balance in the context of a chronic illness experience has previously been described (Heaton et al., 2015). People with chronic inflammatory arthritis, for instance, have described how they experience the process of coping with their chronic condition as a dynamic, iterative, balancing process (Grønning et al., 2011). Similarly, Jarrett (2000) has described the length that people experiencing chronic illness are willing to go to in order to find the balance between living a life and living an illness (Jarrett, 2000). Adjusting to changes in illness patterns, and the impact of these on life experiences and expectations has also been reported by Kralik (2002), who have identified that patients often have to go through distinct phases in balancing different life expectations with the desire to learn how to live with their illness and perhaps get well again. Similarly, Whittmore and Dixon (2008) have written in detail about the desire for those with a range of chronic illnesses to successfully integrate their chronic illness experience into a meaningful life experience, and the challenges related to self-management strategies and overcoming the demands of their illness. They discussed within the themes of integration that they identified, notions of: shifting sands, staying afloat, weathering the storm, rescuing oneself and navigating life. In terms of shifting sands, like our ideas around the concept of ebb-tide, participants in their study went to quite extreme efforts to integrate their illness experiences smoothly into their life experiences. Not always fully successfully, and when less successful it left them feeling like they were on shaky ground. 


\section{Illness as emplaced: physical and symbolical aspects}

When the participants describe how various places impact on their illness experiences, they reflect on both physical and symbolic aspects. When they refer to place as a concrete immediate physical environment, such as a bed, a sofa, a book, a kitchen, a refrigerator, a shop, a theatre or a busy street, they describe how the physical aspects of these places makes them feel soothed, threatened, imprisoned or freed. These descriptions are often related either to sensory impressions that become too strong for them (light, temperature and sounds) or sensory impressions that they enjoy (such as birdsong and the beauty of natural landscapes).

Equally often, however, place comes across in their descriptions as a construct of experience that exceeds its mere physicality. These places are as 'real' to the experiencer as any conventional physical location. When they describe these experiences, they convey the symbolic meaning and value they ascribe to them. These meanings emerge from people who experience the physicality of places, and consciously apply cultural definitions to their symbolic aspects. Natural landscapes, for instance, symbolises freedom, light, hope, beauty and tranquillity. Freedom is something the participants feel very strongly about, either in terms of feeling it, striving for it, or mourning its absence. They often present physical and symbolic aspects as closely entwined, and sometimes as mutually dependent on each other: feelings of loneliness can be intensified by hearing sounds such as "noises of the family" or "happy children's voices far away", or looking at certain artefacts that remind them of what they "miss and long for", such as unused dancing shoes, a boat that unloads its cargo in a harbour, and a big bed. They consciously reflect on why these emotions arise: a man explains that negative emotions easily surface when he visits the harbour because there he is "reminded of how it used to be to work and 
travel", a woman explains how she always becomes sad when she goes into the bedroom because there she feels what she misses and long for, and a woman describes how being in her mother's mountain cottage brings her "the experience of being on a mountain hike".

\section{Strengths and limitations}

We perceive the main strengths of our study to be involvement of people with ME in planning the study, the low level of researcher influence, the complementarity of two different data-sources, and the heterogeneity of participants (stretching from a young man with a wife and a new-born baby, to an older woman living on her own). The main weakness of our study is that our data collection method does not allow us to ask participants to elaborate on their stories, which could increase the chance of overinterpreting their stories. In an attempt to minimise this risk we have striven to keep the voice of the participants at the forefront of our presentation of their stories and in our thoughts during our interpretation.

\section{Conclusion}

Based on textual and visual narratives, we have explored the role of place in shaping the ways in which people with ME experience, manage and endure their debilitating chronic illness. Through detailed and comprehensive stories, they describe how they interpret, attach meaning to, experience and adapt to the places in which they reside in their everyday lives, particularly the places where they experience their illness as least and most taxing. Most of all, they describe how and why nearly every place they inhabit become places they escape to and from because they relieve or intensify their illness experience. By explicitly reflecting on various links between the physical and 
the symbolic, the participants exhibit deeply thoughtful views on their 'sense of place'.

\section{References}

Anderson VR, Hlavaty LE, Jason LA, et al. (2012) A review and meta-synthesis of qualitative studies on Myalgic Encephalomyelitis/chronic fatigue syndrome. Patient Education and Counselling 86(2): 147-155.

Andrews GJ (2015) The lively challenges and opportunities of non-representational theory: A reply to Hanlon and Kearns. Social Science and Medicine (128): $338-341$.

Lian OS (2007) Rural doctors on a global stage: Do local communities make a difference? Social Theory \& Health 5(1): 88-120.

Lian OS and Bondevik H (2015) Medical constructions of long-term exhaustion, past and present. Sociology of Health \& Illness 37(6): 920-935.

Lian OS and Hansen AH (2015) Factors facilitating patient satisfaction among women with medically unexplained long-term fatigue: A relational perspective. Health. Epub ahead of print 14 May. DOI: $10.1177 / 1363459315583158$.

Lian OS and Nettleton S (2015) 'United we stand'. Framing myalgic encephalomyelitis in a virtual symbolic community. Qualitative Health Research 25(10): 1383-1394.

Braun V and Clarke V (2006) Using thematic analysis in psychology. Qualitative Research in Psychology 3(2): 77-101.

Brurberg KG, Flottorp S, Fønhus MS, Larun L and Malterud K (2014) Case definitions for chronic fatigue syndrome/myalgic encephalomyelitis (CFS/ME): A systematic review. British Medical Journal Open, 74(2): Article e003973. 
Casey ES (1997) The fate of place. A philosophical history. Berkely: University of California Press.

Casey ES (2001) Between geography and philosophy: what does it mean to be in the place-world?." Annals of the Association of American Geographers 91(4): 683-693.

Carruthers BM, De Meirleir KL, van de Sande MI, et. al. (2003) Myalgic encephalomyelitis: International Consensus Criteria. Journal of International Medicine 270(4): 327-338.

Charmaz K (2014) Constructing grounded theory. Los Angeles: Sage.

Crooks VA and Chouinard V (2006) An embodied geography of disablement: Chronically ill women's struggles for enabling places in spaces of health care and daily life. Health \& Place (12)3: 345-352.

Domosh M and Seager J (2001) Putting women in place: feminist geographers make sense of the world. New York: Guilford Press.

Drachler ML, Leite JC, Hooper L, et al. (2009) The expressed needs of people with chronic fatigue syndrome/myalgic encephalomyelitis: a systematic review. BMC Public Health 9(1): 458.

Drew S and Guillemin M (2014) From photographs to findings: visual meaning making and interpretive engagement in the analysis of participant-generated images. Visual Studies 29(1): 54-67.

Edwards CR, Thompson AR and Blair A (2007) An 'overwhelming illness'. Women's experiences of learning to live with chronic fatigue syndrome/myalgic encephalomyelitis. Journal of Health Psychology 12(2): 203-214.

Eyles J (1985) Senses of place. Warrington: Silverbrook.

Gesler WM (1992) Therapeutic landscapes: medical issues in light of the new cultural geography. Social Science and Medicine 34(7): 735-746.

Gesler WM and Kearns RA (2002) Culture/place/health. London: Routledge. 
Gieryn TF (2000) A place for space in sociology. Annual Review of Sociology (26): 463-496.

Grønning K, Lomundal B, Koksvik HS and Steinsbekk A (2011). Coping with arthritis is experienced as a dynamic balancing process. A qualitative study. Clinical rheumatology 30(11): 1425-1432.

Harper D (2012) Visual sociology. London: Routledge.

Heaton J, Räisänen U and Salinas M (2015). 'Rule your condition, don't let it rule you': young adults' sense of mastery in their accounts of growing up with a chronic illness. Sociology of health \& illness, DOI: 10.1111/1467-9566.12298.

Jarrett L (2000) Living with chronic illness: a transitional model of coping. British Journal of Therapy and Rehabilitation 7(1): 40-44.

Kearns RA (2014) The health in "life's infinite doings": A response to Andrews et al. Social Science and Medicine (115): 147-149.

Kralik D (2002) The quest for ordinariness: transition experienced by midlife Women living with chronic illness. Journal of Advanced Nursing 39(2): 146-154.

Larun L and Malterud K (2007) Identity and coping experiences in Chronic

Fatigue Syndrome: a synthesis of qualitative studies. Patient Education and Counselling (69): 20-28.

Moss P and Dyck I (2002) Women, body, illness: Space and identity in the everyday lives of women with chronic illness. Rowman \& Littlefield Publishers.

Nacul LC, Lacerda EM and Campion P, et al. (2011) The functional status and wellbeing of people with myalgic encephalomyelitis/chronic fatigue syndrome and their carers. BMC Public Health 1(11): 402.

Pini B and Soldatic K (2012) Women, Chronic Illness, and Rural australia: exploring the Intersections between space, Identity, and the Body. In: Leipert B, Leach B and Thurston WE (eds) Rural Women's Health. Toronto: University of Toronto Press, pp. 385-402. 
Radley A and Taylor D (2003) Images of recovery: A photo-elicitation study on The hospital ward. Qualitative Health Research 13(1):77-99.

Rapport F, Doel A and Elwyn G (2007) Snapshots and snippets: General practitioners' reflections on professional space. Health \& Place 13(2): 532544.

Rugg LH (1997) Picturing ourselves: Photography and autobiography. University of Chicago press.

Søderlund A, Skoge AM and Malterud K, (2000) "I could not lift my arm holding The fork...". Living with chronic fatigue syndrome. Scandanavian Journal Primary Health Care 18(3):165-169.

van Manen M (1990) Researching Lived Experience. SUNY Press, New York.

Wang C and Burris MA (1997) Photovoice: Concept, methodology, and use for participatory needs assessment. Health Education and Behavior 24(3): 369387.

Whitehead LC (2006) Quest, chaos and restitution: Living with chronic fatigue syndrome/myalgic encephalomyelitis. Social Science and Medicine 62(9): 2236-2245.

Whittmore R and Dixon J (2008) Chronic Illness: the process of integration. The Journal of Chronic Illness 17(7B): 177-187. 
Attachment:

Photographs (all photographs are copyright protected)

Photograph W4: My bed

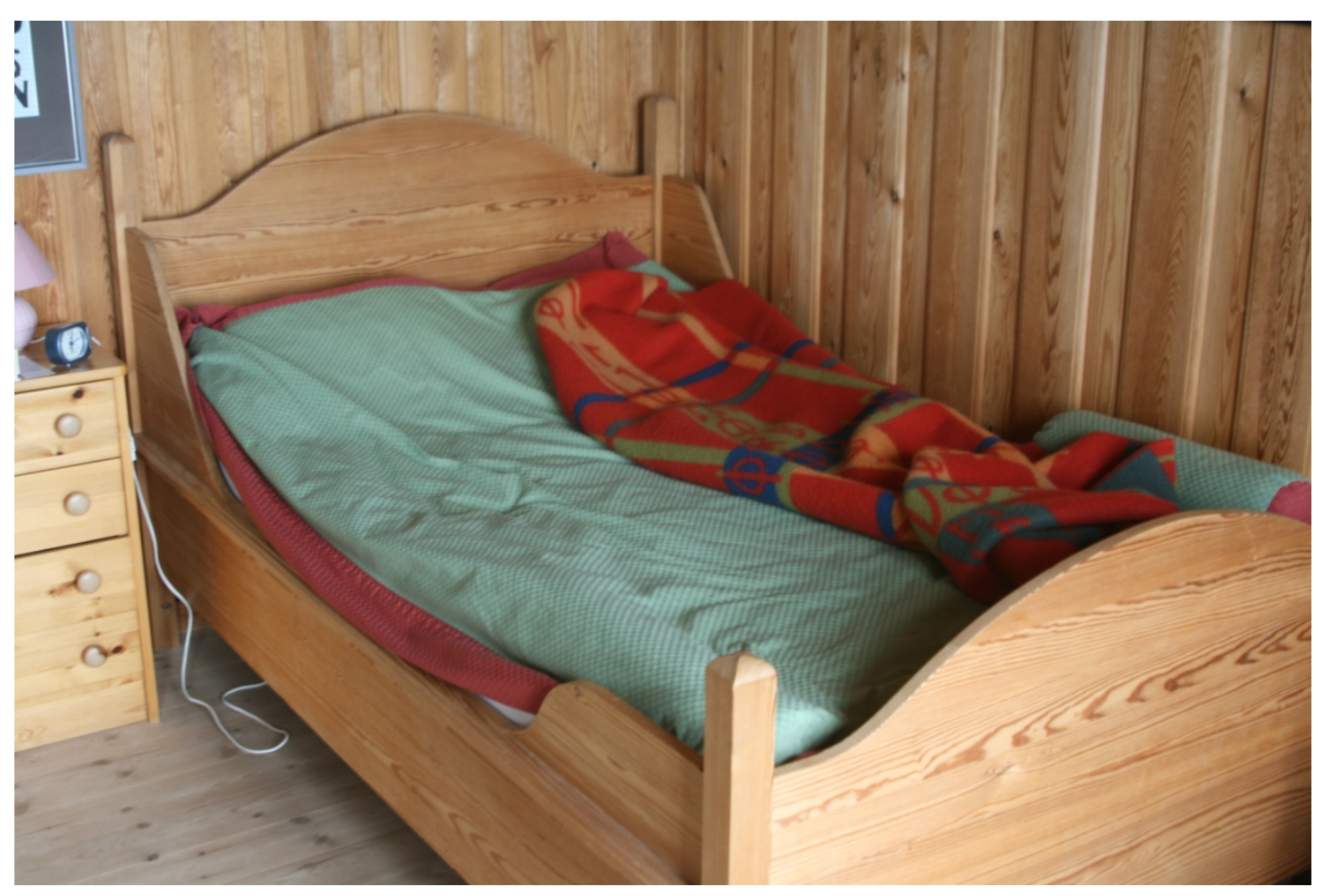


Photograph W3: The sleeping couch

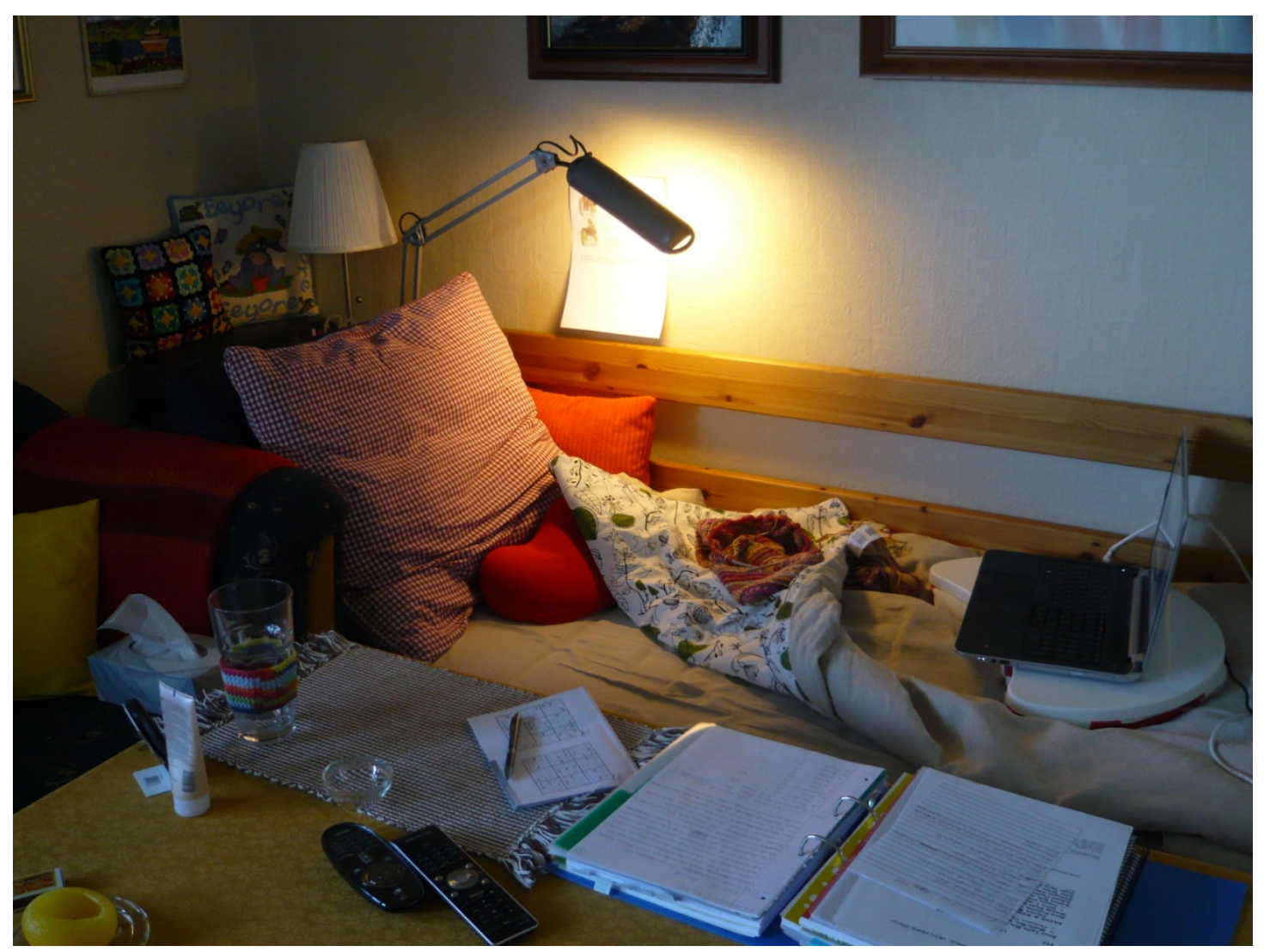


Photograph W2: The kitchen

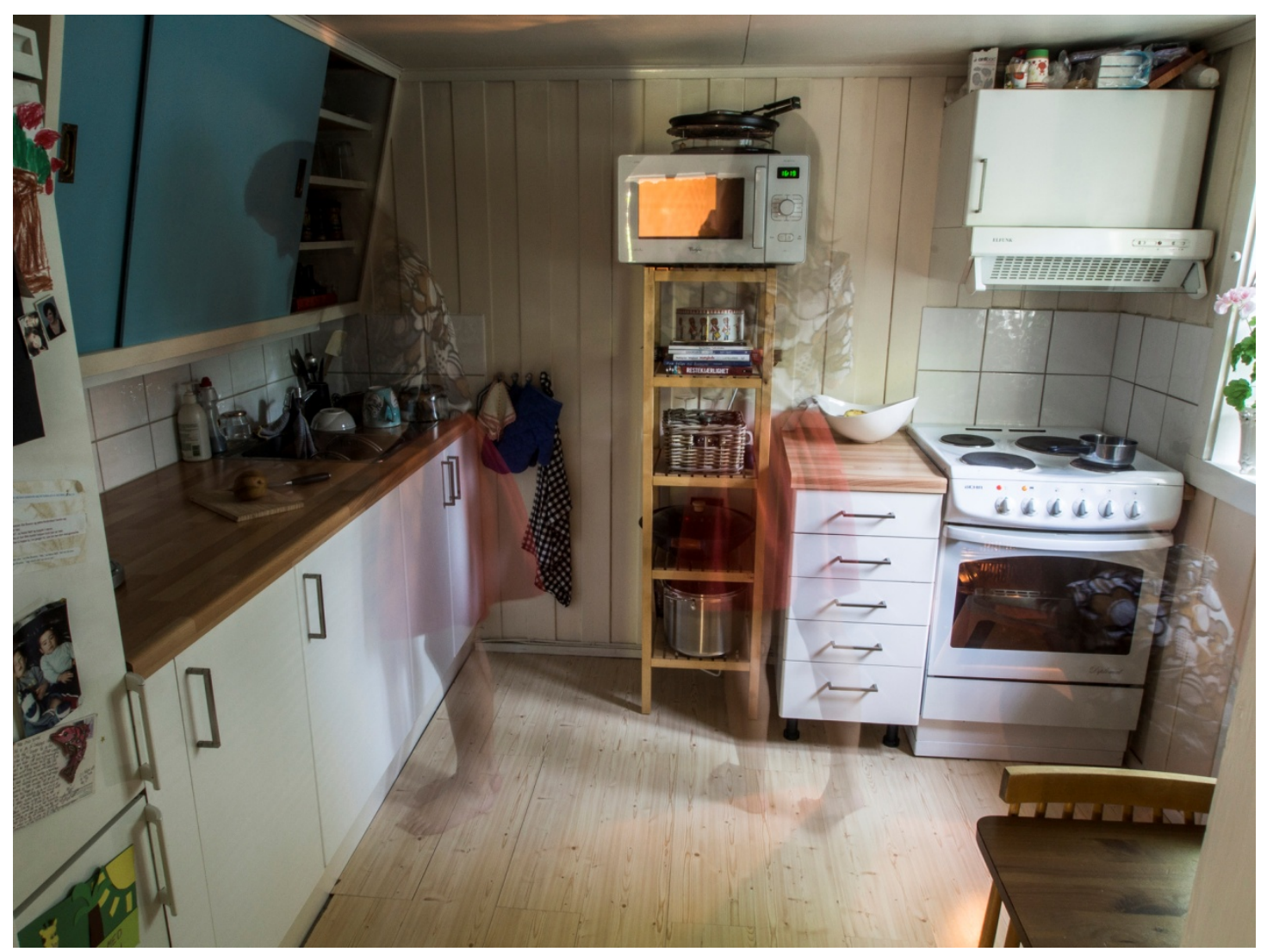


Photograph M1: The letter

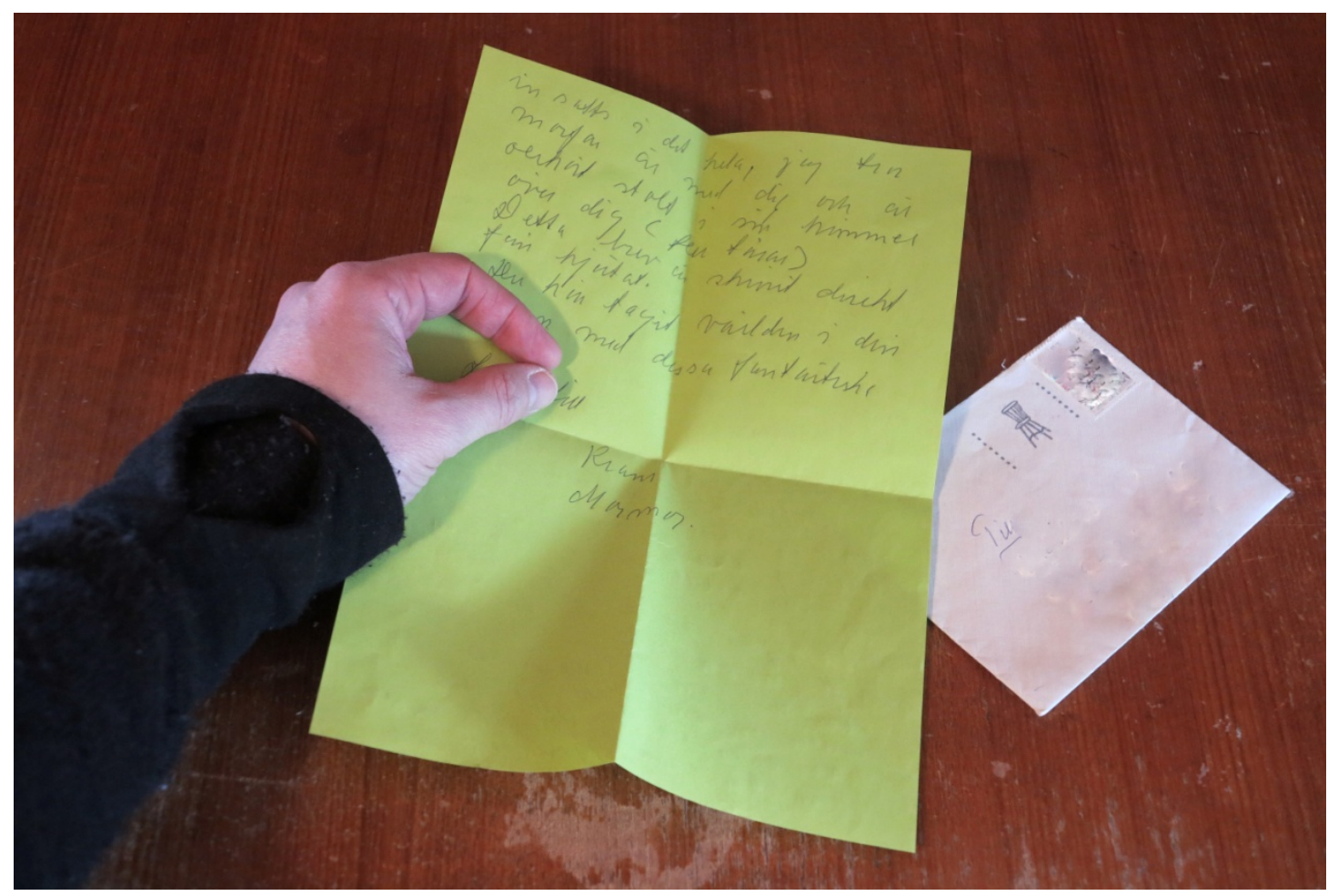


Photograph M3: Unloading at the harbour

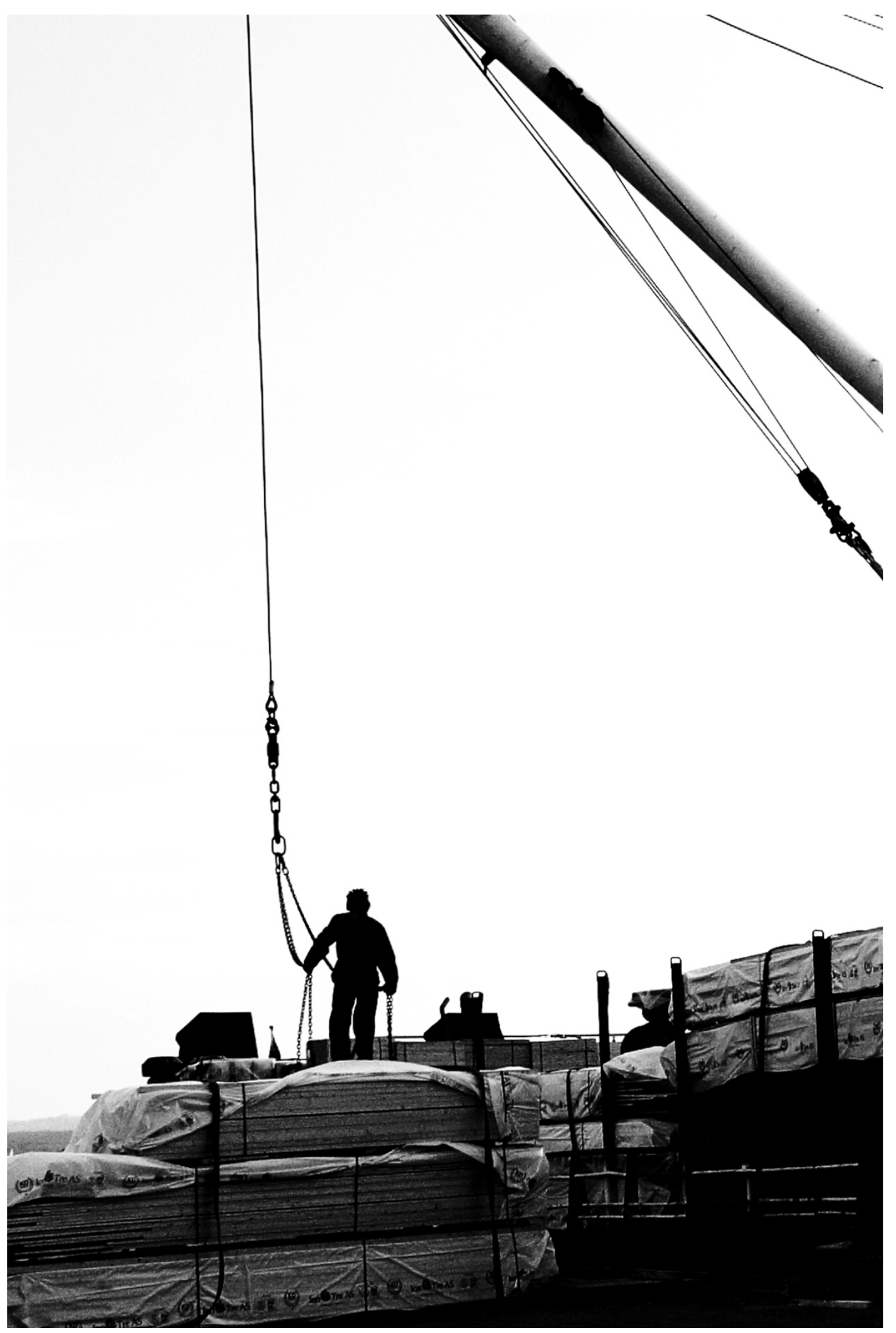


Photograph W6: Where the eye don't stop

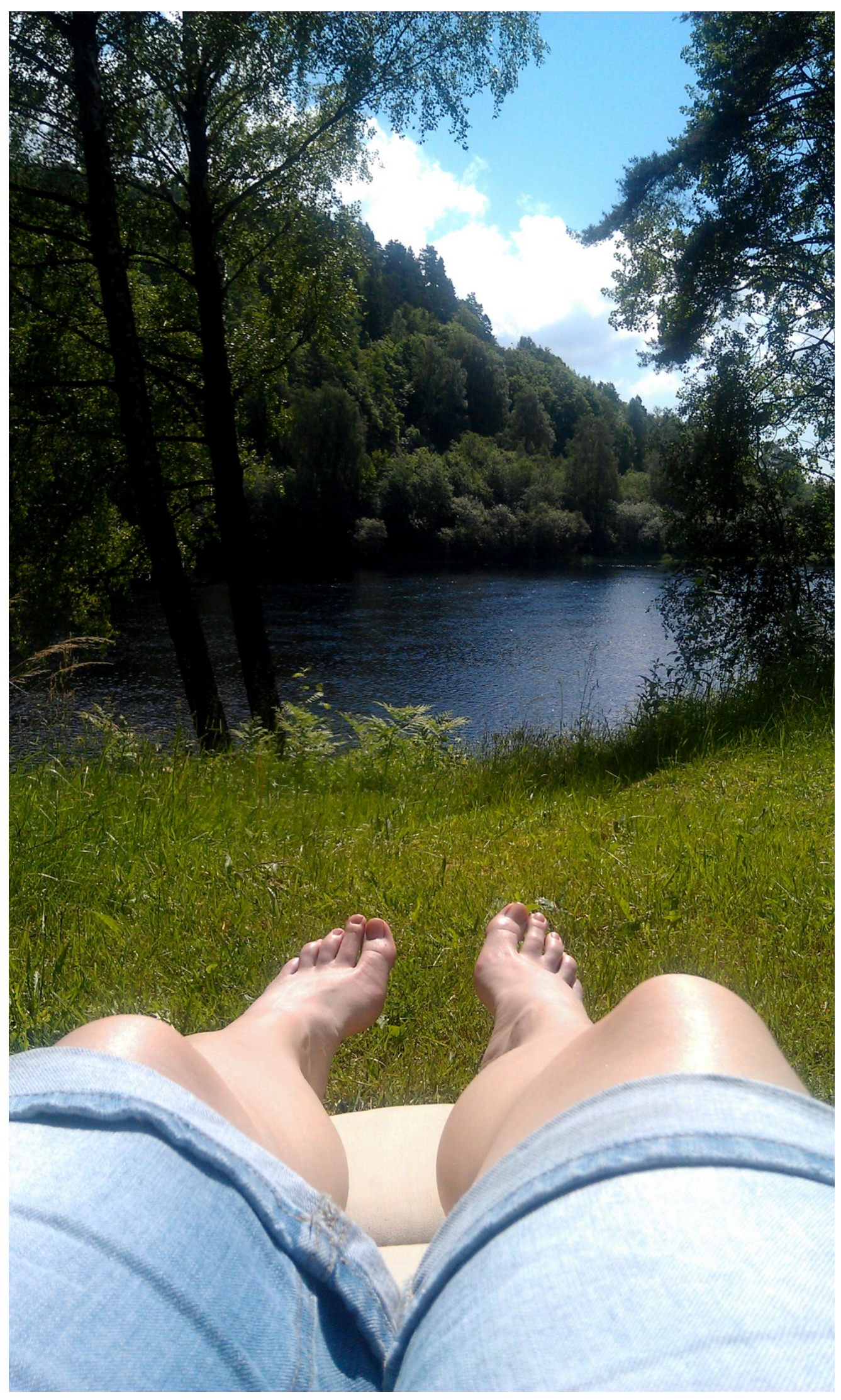


